\section{High-frequency Shoot Regeneration from Roots of Japanese Persimmon}

\author{
Takuya Tetsumura and Hisajiro Yukinaga \\ Experimental Farm, Faculty of Agriculture, Kyoto University, Takatsuki, \\ Osaka 569, Japan
}

Additional index words. auxin, cytokinin, Diospyros kaki, in vitro, root length

\begin{abstract}
Microshoots of Japanese persimmon (Diospyros kaki L. cv. Jiro) were rooted in vitro. The roots were excised and cultured on solidified Murashige and Skoog medium. After 20 days of culture, adventitious shoots formed spontaneously and directly from the roots. Of all the tested cytokinins, $10^{-5} \mathrm{M}$ zeatin in combination with $10^{-8} \mathrm{M}$ IAA was the most effective in stimulating production of adventitious shoots. CPPU and $2 \mathrm{iP}$ also were effective cytokinins. Addition of a high concentration of auxin, especially 2,4-D, to the medium inhibited adventitious shoot formation. The percentage of root segments forming adventitious shoots increased with increasing segment length. Almost all of the longest roots $(4$ to $6 \mathrm{~cm}$ ) formed adventitious shoots. Chemical names used: 6-benzyladenine (BA); 2,4-dichlorophenoxyacetic acid (2,4-D); indole-3-acetic acid (IAA); 2-isopentenyladenine (2iP); $N$-phenyl- $N^{\prime}$-(2-chloro-4-pyridyl)urea (CPPU).
\end{abstract}

Methods for micropropagation of Japanese persimmon have been developed previously (Tao and Sugiura, 1992a). However, their application to commercial production has been limited, because Japanese persimmon microcuttings generally are difficult to root. More than half of the cultivars tested by Fukui et al. (1992) had low rooting ability. Although shoots proliferated with the aid of BA rooted better than those proliferated with zeatin, few cultivars could be established in vitro using BA (Tetsumura et al., 1991).

Furukawa et al. (1990) reported that shoots regenerated from root cultures of Eustoma grandiflorum (Griseb.) Schinners rooted easily and that root organ culture seemed to be useful for their micropropagation. Similarly, if microshoot regeneration from roots of Japanese persimmon cultivars that have low rooting ability can be obtained easily, the feasibility of their micropropagation will be greatly enhanced. However, to our knowledge, there have been no reports of in vitro shoot regeneration from roots of Japanese persimmon. In preliminary experiments, we succeeded in inducing in vitro shoot regeneration from roots of some Japanese persimmon cultivars, although the rate of such shoot formation was low. Therefore, our objective was to obtain high-frequency shoot regeneration from roots of Japanese persimmon by investigating the influence of growth regulators, length of root explants, and whether root explants had an apical meristem on shoot regeneration from roots.

Received for publication 22 May 1995. Accepted for publication 5 Jan. 1996. This work was supported, in part, by grant-in-aid no. 04760022 from the Ministry of Education, Science, and Culture, Japan. The cost of publishing this paper was defrayed in part by the payment of page charges. Under postal regulations, this paper therefore must be hereby marked advertisement solely to indicate this fact.

HortScience, Vol. 31(3), June 1996
Root length and root apex. Root segments with or without a root apex were cut to either $1,2,3$ to 4 , or 4 to $6 \mathrm{~cm}$ long and cultured on MS medium supplemented with $10^{-5} \mathrm{M}$ zeatin and $10^{-8} \mathrm{M}$ IAA. There were 18 to 20 roots per treatment.

Analytical methods. Each experiment was conducted twice. The percentage of root segments forming adventitious shoots was determined after 60 days of culture. The number of root segments forming more than five adventitious shoots also was recorded. Percentage data were subjected to arcsin transformation and then significance of treatment effects was determined using analysis of variance (ANOVA). Variation among treatment means was analyzed using Tukey's (1953) procedure.

\section{Results and Discussion}

After 20 days of culture, adventitious shoots differentiated spontaneously from roots (Fig. 1). The shoots arose directly from root tissue, not from callus, in the same way as previously reported in red raspberry (Rubus ideaus L.) (Borgman and Mudge, 1986) and prairie gentian [Eustoma grandiflorum (Griseb.) Schinners] (Furukawa et al., 1990).

Growth regulators. All the cytokinins tested induced adventitious shoot formation on roots (Table 1). When no cytokinin was present in the medium, adventitious shoot formation did not occur. In comparing various kinds of cytokinins at several concentrations in combination with $10^{-8} \mathrm{M}$ IAA, the best result in terms of percent root segments forming adventitious shoots was obtained with $10^{-5} \mathrm{M}$ zeatin, although the effectiveness of this treatment did not differ significantly from that of several others. This effect of zeatin is similar to that reported for adventitious bud formation from callus (Tao and Sugiura, 1992b) and shoot tip cultures (Cooper and Cohen, 1984; Tetsumura et al., 1991) of Japanese persimmon. The concentrations of CPPU were set an order of magnitude lower than those of the other cyto-

Table 1. Effect of various types of cytokinins at several concentrations on adventitious shoot formation from roots of 'Jiro' Japanese persimmon. All media contained $10^{-8}$ M IAA. Pure Chemicals Co., Tokyo) and $0.09 \mathrm{M} \mathrm{su}-$ crose. The $\mathrm{pH}$ of the media was adjusted to 5.7 before autoclaving at $121 \mathrm{C}$ and $120 \mathrm{kPa}$ for 15 $\mathrm{min}$. Two to four root segments were placed in each Erlenmeyer flask $(100 \mathrm{ml})$ containing 30 $\mathrm{ml}$ of the differentiation medium. Cultures were maintained at $28 \mathrm{C}$ under a $16-\mathrm{h} /$ day photoperiod with a photon flux of 60 $\mu \mathrm{mol} \cdot \mathrm{m}^{-2} \cdot \mathrm{s}^{-1}$ provided by cool-white fluorescent lamps.

Growth regulators. Terminal root segments, including the root apex, were cut to 4.5 $\pm 1.5 \mathrm{~cm}$ long and cultured on MS medium supplemented with either zeatin, CPPU, BA, or $2 \mathrm{iP}$ (see Table 1 for concentrations) in combination with $10^{-8} \mathrm{M}$ IAA, or on MS medium containing IAA, IBA, 1-naphthaleneacetic acid (NAA), or 2,4-D at $10^{-9}, 10^{-8}$, and $10^{-7} \mathrm{M}$ in combination with $10^{-5} \mathrm{M}$ zeatin. There were 18 to 20 roots per treatment.

\begin{tabular}{lccc}
\hline \hline & & \multicolumn{2}{c}{$\begin{array}{c}\text { Percent root } \\
\text { segments forming }\end{array}$} \\
Cytokinin & Concn & \multicolumn{2}{c}{ adventitious shoots } \\
\cline { 2 - 4 } Zeatin & $(\mathrm{M})$ & $0 \mathrm{a}^{\mathrm{z}}$ & $0 \mathrm{a}$ \\
& $10^{-6}$ & $35 \mathrm{~b}$ & $3 \mathrm{ab}$ \\
CPPU & $10^{-5}$ & $85 \mathrm{~d}$ & $48 \mathrm{~d}$ \\
& $10^{-4}$ & $53 \mathrm{bc}$ & $43 \mathrm{~d}$ \\
& $10^{-7}$ & $0 \mathrm{a}$ & $0 \mathrm{a}$ \\
BA & $10^{-6}$ & $76 \mathrm{~cd}$ & $34 \mathrm{~cd}$ \\
& $10^{-5}$ & $50 \mathrm{bc}$ & $15 \mathrm{a}-\mathrm{d}$ \\
& $10^{-6}$ & $0 \mathrm{a}$ & $0 \mathrm{a}$ \\
2iP & $10^{-5}$ & $33 \mathrm{~b}$ & $5 \mathrm{a}-\mathrm{c}$ \\
& $10^{-4}$ & $0 \mathrm{a}$ & $0 \mathrm{a}$ \\
& $10^{-6}$ & $3 \mathrm{a}$ & $0 \mathrm{a}$ \\
& $10^{-5}$ & $63 \mathrm{~cd}$ & $30 \mathrm{~b}-\mathrm{d}$ \\
& $10^{-4}$ & $70 \mathrm{~cd}$ & $55 \mathrm{~d}$ \\
\hline
\end{tabular}

${ }^{2}$ Mean separation in columns by Tukey's test $(P \leq$ $0.05)$. Values are means of two replications consisting of 18 to 20 roots each. 


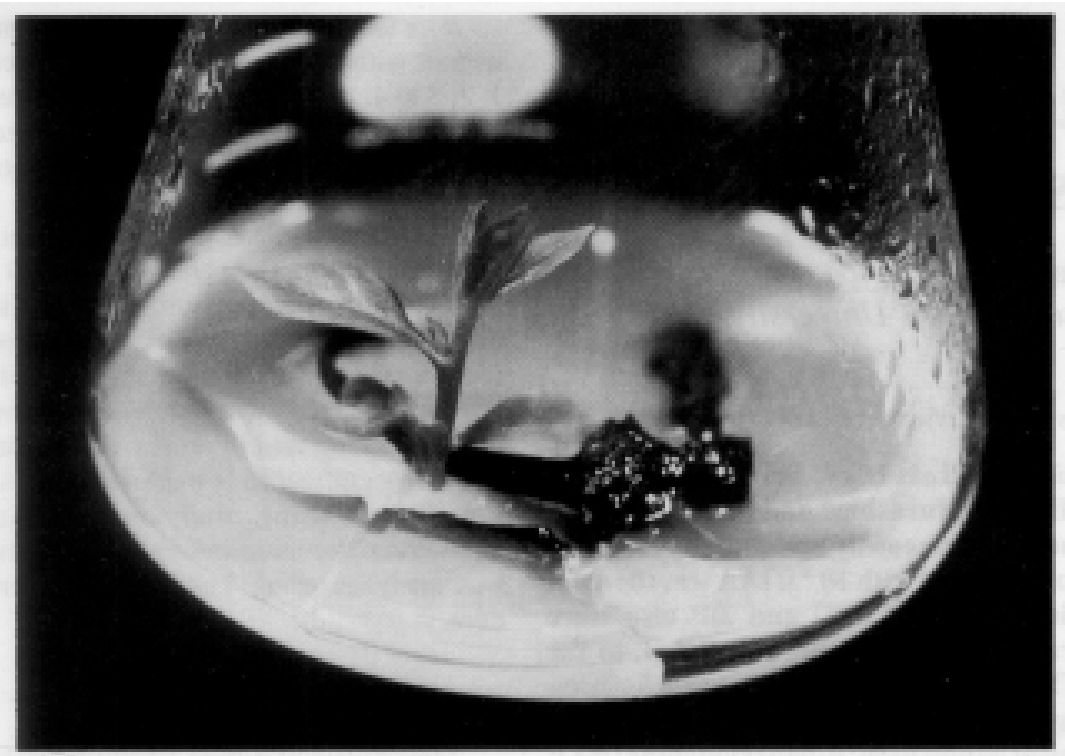

Fig. 1. Adventitious shoot formation from root culture of 'Jiro' Japanese persimmon on solidified MS medium supplemented with $10^{-5} \mathrm{M}$ zeatin and $10^{-8} \mathrm{M}$ IAA after 40 days of culture.

kinins, because several substituted pyridyl phenylurea compounds have been demonstrated to stimulate in vitro meristem and shoot formation at unusually low concentrations (Mok et al., 1987). The two best CPPU concentrations tested for adventitious shoot formation were lower than similarly effective ones for other cytokinins. The natural cytoki$\operatorname{nin} 2 \mathrm{iP}$ effectively induced adventitious shoots from roots and also stimulated shoot elongation (Sugiura et al., 1986), but it had little effect on adventitious bud formation from callus cultures (Tao and Sugiura, 1992b). BA mostly was less effective than the other cytokinins. If the shoots regenerated from roots are wanted for an experiment, $10^{-4} \mathrm{M}$ zeatin and $10^{-5} \mathrm{M}$ CPPU also will be useful because they can induce many adventitious shoots.

Auxin was not essential to produce adventitious shoots on roots, and at higher concentrations, especially $2,4-\mathrm{D}$, stimulated excessive growth of callus and inhibited adventitious shoot formation (data not presented).

Root length and root apex. According to ANOVA, there was no significant effect of the presence of a root apical meristem and no significant interaction between it and root length $(P \leq 0.05)$. The percentage of root segments forming adventitious shoots increased with increasing segment length (Table 2 ), and the regression equation between them $[\mathrm{y}(\%)=-8.72+22.2 \mathrm{x}$ (length)] showed a high correlation $\left(P \leq 0.001, r^{2}=0.90\right)$. Almost all of the 4- to 6-cm root segments formed adventi- tious shoots. In preliminary experiments, we cut roots into small pieces and placed them on the medium. Adventitious shoot formation scarcely occurred. The percentage of 3- to 4$\mathrm{cm}$ root segments forming many adventitious shoots was similar to that for $4-$ to $6-\mathrm{cm}$ segments. Yamada et al. (1988) showed that root length is important for the regeneration of Japanese persimmon from root cuttings.

In this study, we succeeded in obtaining high-frequency shoot regeneration from roots of Japanese persimmon. It seems likely that this high organogenetic potential of roots relates to juvenility, for Tamura et al. (1992) suggested that rejuvenated Japanese persimmon callus had a high capacity of adventitious bud formation, while Bonga (1982) reported that roots often retain juvenility. If shoots regenerated from roots succeed in retaining juvenility, they can easily root and be micropropagated.

\section{Literature Cited}

Bonga, J.M. 1982. Vegetative propagation in relation to juvenility, maturity, and rejuvenation, $\mathrm{p}$. 387-412. In: J.M. Bonga and D.J. Durzan (eds.). Tissue culture in forestry. Martinus Nijhoff, The Hague, The Netherlands.

Borgman, C.A. and K.W. Mudge. 1986. Factors affecting the establishment and maintenance of 'Titan' red raspberry root organ cultures. Plant Cell, Tissue Organ Cult. 6:127-137.

Cooper,P.A. and D. Cohen. 1984. Micropropagation of Japanese persimmon (Diospyros kaki). Com-
Table 2. Effect of root length on adventitious shoot formation from roots of 'Jiro' Japanese persimmon. All media contained $10^{-5} \mathrm{M}$ zeatin and $10^{-8}$ M IAA.

\begin{tabular}{llr}
\hline \hline \multirow{2}{*}{$\begin{array}{ll}\text { Root length } \\
(\mathrm{cm})\end{array}$} & \multicolumn{2}{c}{$\begin{array}{c}\text { Percent root segments } \\
\text { forming adventitious shoots }\end{array}$} \\
\cline { 2 - 3 } & Total & $>5$ \\
\hline 1 & $16 \mathrm{a}^{\mathrm{z}}$ & $1 \mathrm{a}$ \\
2 & $26 \mathrm{a}$ & $6 \mathrm{a}$ \\
$3-4$ & $81 \mathrm{~b}$ & $42 \mathrm{~b}$ \\
$4-6$ & $98 \mathrm{c}$ & $54 \mathrm{~b}$ \\
\hline
\end{tabular}

${ }^{2}$ Mean separation in columns by Tukey's test $(P \leq$ $0.05)$. Values are means of four replications consisting of 18 to 20 roots each.

bined Proc. Intl. Plant Propagators' Soc. 34:118124.

Fukui, H., K. Nishimoto, and M. Nakamura. 1992. Varietal differences in rooting ability of in vitro subcultured Japanese persimmon shoots. J. Jpn. Soc. Hort. Sci. 60:821-825.

Furukawa, H., C. Matsubara, and N. Shigematsu. 1990. Shoot regeneration from the roots of prairie gentian [Eustoma grandiflorum (Griseb.) Schinners]. Plant Tissue Cult. Lett. 7:11-13.

Mok, M.C., D.W.S. Mok, J.E. Turner, and C.V. Mujer. 1987. Biological and biochemical effects of cytokinin-active phenylurea derivatives in tissue culture system. HortScience 22:11941197.

Murashige, T. and F. Skoog. 1962. A revised medium for rapid growth and bioassays with tobacco tissue culture. Physiol. Plant. 15:473497.

Sugiura, A., R. Tao, H. Murayama, and T. Tomana. 1986. In vitro propagation of Japanese persimmon. HortScience 21:1205-1207.

Tamura, M., R. Tao, and A. Sugiura. 1992. Highly stable regeneration from long-term cultures of Japanese persimmon callus. HortScience 27:1048

Tao, R. and A. Sugiura. 1992a. Micropropagation of Japanese persimmon (Diospyros kaki L.), p. 424-440. In: Y.P.S. Bajaj (ed.). Biotechnology in agriculture and forestry, vol. 18: High-tech and micropropagation II. Springer-Verlag, Berlin.

Tao, R. and A. Sugiura. 1992b. Adventitious bud formation from callus cultures of Japanese persimmon. HortScience 27:259-261.

Tetsumura, T., R. Tao, and A. Sugiura. 1991. Effect of cytokinin types on the in vitro propagation of Japanese persimmon (Diospyros kaki Thunb.) (in Japanese with English summary). Plant Tissue Cult. Lett. 8:209-211.

Tukey, J.W. 1953. Some selected quick and easy methods of statistical analysis. Trans. N.Y. Acad. Sci. Ser. II 16:88-97.

Yamada, M., T. Sumi, A. Kurihara, and H. Yamane. 1988. Effects of various factors on the regeneration of Japanese persimmon (Diospyros kaki Thunb.) from root cuttings (in Japanese with English summary). Bul. Fruit Tree Res. Sta. E7:9-30. 